Brit. J. industr. Med., 1973, 30, 162-166

\title{
Respiratory cancer in relation to occupational exposures among retired asbestos workers ${ }^{1}$
}

\author{
PHILIP ENTERLINE, PIERRE DE COUFLE ${ }^{2}$, and VIVIAN HENDERSON \\ Department of Biostatistics, Graduate School of Public Health, University of Pittsburgh, \\ Pittsburgh, Pennsylvania, U.S.A.
}

Enterline, P., de Coufle, P., and Henderson, V. (1973). British Journal of Industrial Medicine, 30, 162-166. Respiratory cancer in relation to occupational exposures among retired asbestos workers. A cohort of 1348 men who completed their working lifetime in the asbestos industry and retired with an industry pension during the period 1941-67 was observed through 1969 for deaths. The average length of employment in the asbestos industry for these men was 25 years and all had exposures to asbestos dust. In some instances these exposures were very high and continued for many years. Mortality for this cohort of men after age 65 was $14.7 \%$ higher than for the entire population of United States white men living at the same ages and time periods. This excess was due almost entirely to cancer and respiratory disease. The cancer excess was chiefly due to respiratory cancer where mortality was 2.7 times the expected. The respiratory disease excess was entirely due to asbestosis.

A time-weighted measure of asbestos dust exposure at the time of retirement was calculated for each man. This was made up of the summed products of dust levels for each job (expressed in mppcf) and years at each level. This measure was directly related to the respiratory cancer excess at ages 65 and over, ranging from 1.7 times expected for men with less than 125 mppcf-years exposure to 5.6 times expected for men with 750 or more mppcf-years exposure. There appeared to be no direct relationship between asbestos dust exposure and respiratory cancer below 125 mppcf-years. Important increments in respiratory cancer mortality apparently occurred somewhere between 100 and 200 mppcf-years exposure.

Separation of the effects of time from the effects of average dust level on respiratory cancer mortality showed that the contribution of each was about the same and that a time-weighted measure of asbestos dust appears to be an appropriate method for predicting respiratory cancer effects.

There are relatively few studies on the dose-response relationship between asbestos dust and respiratory cancer. In a recent article McDonald et al. (1971) reported on the incidence of respiratory cancer deaths among Canadian asbestos miners in relation

\footnotetext{
${ }^{1}$ A revision of a paper read on 9 February 1972 at the Annual Meeting of the American Academy of Occupational Medicine, Pittsburgh, Pennsylvania, U.S.A.

${ }^{2}$ Currently with the US National Institute of Occupational Safety and Health.
}

to their cumulative asbestos dust exposure. That study suggests that a definite dose-response relationship exists and that below certain measurable levels of asbestos dust there appears to be little or no carcinogenic response. Three earlier studies also suggested a dose-response relationship. Knox, Holmes, Doll, and Hill (1968) found, in a preliminary report, that after dust controls were introduced in a British asbestos textile plant during the 1930s, the incidence of respiratory cancer fell from a 10 -fold excess to a rate similar to that in the general population. Newhouse 
(1969) reported that workers with heavy asbestos dust exposure had an excess of respiratory cancer, whereas those exposed to moderate or light doses had no excess. In a study which compared three segments of the American asbestos industry, Enterline and Kendrick (1967) reported that the estimated levels of asbestos dust related directly to variations in respiratory cancer deaths and to asbestosis deaths.

This is a report on the mortality experiences at ages 65 and over of a group of men who completed their working lifetime as production or maintenance employees in the asbestos industry, who retired with an industry pension, and who were all exposed to asbestos dust in varying degrees in the course of their employment. The average duration of employment in the asbestos industry was 25 years with a range from 3 to 51 years. Historic dust levels were sometimes in excess of 50 million particles per cubic foot of air. For each of these retirees it was possible, by combining personnel records with asbestos dust level estimates for each job and time period, to reconstruct their asbestos dust exposure history and, for each man, to assign a measure of his cumulative asbestos dust exposure at the time of retirement.

The cohort upon which this study is based consisted of all men retiring during the years 1941-67 and deaths occurring among these men through 1969. Such a study could be conducted almost entirely using industry records, except that where deaths occurred official copies of death certificates needed to be obtained. Included in this study were three kinds of retirees-those who retired normally at age 65; those who retired before age 65 for personal reasons but lived to age 65 ; and men who retired before age 65 because of a disability but who lived to be 65 . The observed mortality among these men was compared with an expected mortality based upon the experience of the entire US white male population living in the time-age intervals that characterized the retired population. Inclusion of disabled retirees improves comparability with the US white male population as the latter also includes men unable to work for health reasons. The modified life table method was used for computing the expected number of deaths. This method is widely used and has been described in detail in an earlier report (Enterline, 1965).

There was a total of 1376 men in this study who reached age 65. Of these, complete exposure and job histories were available for 1348 . Dust levels at each job site and time period were expressed as million particles per cubic foot of air (mppcf). It was not possible to estimate very precisely the dust level for each job, particularly for past periods, and dust levels could be only roughly classified. Jobs were placed in one of six classes or ranges, and for calculating total exposure mid-points of the range were used. Classes used were: no exposure (0); under
5 mppcf (2.5); 5-10 mppcf (7.5); 10-30 mppcf (20.0); $30-50$ mppcf $(40 \cdot 0) ; 50$ mppcf or more (62.5).

To compute total dust exposure for each man the dust level at each job and time period was multiplied by years at that job and summed across all jobs. This total cumulative exposure can be thought of as mppcf-years. Thus, if a man with a 30-year work history initially worked 10 years at a job with a dust level at that time of 20.0 mppcf, 10 years at a dust level of $2.5 \mathrm{mppcf}$, and 10 years at a dust level of 7.5 mppcf his total exposure would be: $(10 \times 20)+$ $(10 \times 2.5)+(10 \times 7.5)$ or 300 mppcf-years. His average exposure level would be 10 mppcf.

\section{Results}

Table 1 shows observed and expected deaths and standardized mortality ratios (SMR) for selected causes of death for the entire cohort of 1348 men for whom complete job and exposure data could be obtained. The expected value of the SMR, where observed and expected deaths is the same, is 100 , and deviations from 100 are percentage deviations from expected mortality. As noted above, expected deaths were based upon the mortality experience of the entire US white male population living at the same ages and time periods as the cohort under study. Of the 754 deaths observed, death certificates could be located for 733. It is not known how much SMRs for individual causes of death might be changed were the remaining 21 death certificates available. It is unlikely, however, that there would be much of an increase for any single cause and no attempt has been made to allocate these 21 deaths to cause of death groupings. All death certificates were coded according to the Seventh Revision of the International

\section{TABLE 1}

ObSERVED AND EXPECTED DEATHS, AND SMR FOR Selected Causes of Death, 1348 Males RETIRING FROM THE ASBESTOS INDUSTRY 1941-67 AND FOLLOWED THROUGH 1969

\begin{tabular}{|c|c|c|c|}
\hline Cause of death & Observed & Expected & $S M R$ \\
\hline 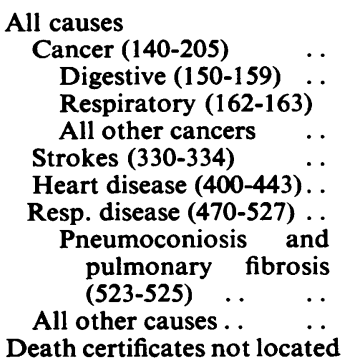 & $\begin{array}{r}754 \\
167 \\
53 \\
58 \\
56 \\
61 \\
326 \\
67\end{array}$ & $\begin{array}{r}657 \cdot 2 \\
109 \cdot 4 \\
41 \cdot 8 \\
21 \cdot 7 \\
45 \cdot 9 \\
77 \cdot 1 \\
306 \cdot 6 \\
36 \cdot 8\end{array}$ & $\begin{array}{r}114.7 \\
152.6 \\
126.8 \\
267 \cdot 3 \\
122 \cdot 0 \\
79.1 \\
106 \cdot 3 \\
182 \cdot 1\end{array}$ \\
\hline
\end{tabular}


Classification of Diseases by a regular coder from the US National Center for Health Statistics. Numbers in parentheses in Table 1 correspond to the International Statistical Classification rubrics.

Table 1 shows that those men who retired from an industry with asbestos dust exposure had an overall mortality rate $14.7 \%$ higher than all US males. This excess is due almost entirely to cancer and disease of the respiratory system. For cancer, the greatest excess is in cancer of the respiratory system (ISC 162, 163) but with some excess also in cancer of the digestive system and other cancers. For respiratory disease the excess is due entirely to peneumoconiosis and pulmonary fibrosis. Eighteen of these deaths were due to asbestosis (ISC 523.2).

Data shown in Table 1 are very similar to data from other studies of asbestos workers which included men at ages under 65 (McDonald et al., 1971; Enterline and Kendrick, 1967; Selikoff, Churg, and Hammond, 1964; Mancuso and Coulter, 1963; Doll, 1955; Elwood, Cochrane, Benjamin, and SeysProsser, 1964). The excess in cancer, and particularly respiratory cancer and digestive cancer, and respiratory disease reported in other studies shows up quite clearly in this population of retired males. This is important since it could be argued that by age 65 men susceptible to an occupational hazard may already have been selected out of a cohort by death, and any effects of occupational exposure could not be detected.

In the analysis which follows only the relationship between asbestos dust exposure and respiratory cancer will be shown. Parallel analyses could, of course, be made for other causes of death.

Table 2 shows the relationship between total dose expressed as mppcf-years and mortality from respiratory cancer. For each dose interval actual means are shown in parentheses. It is quite clear that total dust exposure is highly related to respiratory cancer. If these data are plotted on arithmetic paper this relationship appears to be linear except at the highest dose level.

Of particular interest is the SMR of 166.7 for the 533 men with a total exposure of less than 125 mppcf-years. For a man with 25 years work in the asbestos industry this represents work, on average, at or below the old threshold limit value (TLV) of 5 mppcf. Table 3 divides the 533 men with a total mppcf-years under 125 into three total dust groupings to see if any relationship between dust and respiratory cancer exists within the under 125 mppcf-years' category. As in Table 2, actual means for each dose interval are shown in parentheses. No direct relationship between dust and respiratory cancer excess appears. In fact the relationship appears to be slightly inverse. Whether the SMR for

TABLE 2

Observed ANd EXPeCted Deaths ANd SMR for Respiratory CaNCer (ISC 162-163) By Total Dust EXPOSURE, 1348 MEN RETIRING FROM THE ASBESTOS INDUSTRY 1941-67 AND Followed Through 1969

\begin{tabular}{|c|c|c|c|c|c|c|c|c|}
\hline \multirow{2}{*}{\multicolumn{5}{|c|}{$\begin{array}{c}\text { Total dust exposure } \\
\text { (mppcf-yr) }\end{array}$}} & \multirow[t]{2}{*}{ No. of men } & \multicolumn{3}{|c|}{ Respiratory cancer deaths } \\
\hline & & & & & & Observed & Expected & $S M R$ \\
\hline $\begin{array}{l}\text { Under } 125 \\
125-249 \\
250-400 \\
500-749 \\
7.50 \text { and over }\end{array}$ & $\begin{array}{l}(62 \cdot 9) \\
(181 \cdot 0) \\
(351 \cdot 0) \\
(606 \cdot 1) \\
(960 \cdot 2)\end{array}$ & $\begin{array}{l}\ldots \\
\ldots \\
\ldots \\
\ldots \\
.\end{array}$ & $\begin{array}{l}\ldots \\
\cdots \\
\cdots \\
\ldots\end{array}$ & $\begin{array}{l}. \\
. \\
\ldots \\
. \\
.\end{array}$ & $\begin{array}{r}533 \\
305 \\
328 \\
126 \\
56\end{array}$ & $\begin{array}{r}15 \\
12 \\
17 \\
9 \\
5\end{array}$ & $\begin{array}{l}9 \cdot 0 \\
4 \cdot 8 \\
5 \cdot 2 \\
1 \cdot 8 \\
0 \cdot 9\end{array}$ & $\begin{array}{l}166 \cdot 7 \\
250 \cdot 0 \\
326 \cdot 9 \\
500 \cdot 0 \\
555 \cdot 6\end{array}$ \\
\hline
\end{tabular}

TABLE 3

Observed and EXPeCted Deaths and SMR for Respiratory CanCer (ISC 162-163), 533 Men with TOTAL DUST EXPOSURE Below 125 mppcf-yr, RETIRING FROM THE ASBESTOS INDUSTRY 1941-67 AND FOLLOWED THROUGH 1969

\begin{tabular}{|c|c|c|c|c|c|c|c|c|}
\hline \multirow{2}{*}{\multicolumn{5}{|c|}{$\begin{array}{c}\text { Total dust exposure } \\
\text { (mppcf/yr) }\end{array}$}} & \multirow{2}{*}{ No. of men } & \multicolumn{3}{|c|}{ Respiratory cancer deaths } \\
\hline & & & & & & \multirow{2}{*}{$\begin{array}{c}\text { Observed } \\
2 \\
8 \\
5\end{array}$} & \multirow{2}{*}{$\begin{array}{c}\text { Expected } \\
1 \cdot 3 \\
3 \cdot 1 \\
4.6\end{array}$} & \multirow{2}{*}{$\begin{array}{l}S M R \\
153 \cdot 8 \\
258 \cdot 1 \\
108 \cdot 7\end{array}$} \\
\hline $\begin{array}{l}\text { Under } 25 \cdot 0 \\
25 \cdot 0-62 \cdot 4 \\
62 \cdot 5-124 \cdot 9\end{array}$ & $\begin{array}{l}(11 \cdot 1) \\
(44 \cdot 4) \\
(89 \cdot 1)\end{array}$ & $\begin{array}{l}\cdots \\
\cdots \\
\cdots\end{array}$ & $\begin{array}{l}\cdots \\
\cdots \\
\cdots\end{array}$ & $\begin{array}{l}\cdots \\
\cdots \\
\cdots\end{array}$ & $\begin{array}{r}75 \\
181 \\
277\end{array}$ & & & \\
\hline
\end{tabular}


respiratory cancer of $\mathbf{1 6 6 . 7}$ for men in the lowest exposure category is related to asbestos dust or to something else cannot definitely be established from these data. One of the factors that probably elevates somewhat this SMR is the fact that the men in this study were mainly urban dwellers and respiratory cancer death rates are normally higher in urban than in non-urban areas. Thus, since the expected number of deaths is based on the entire United States it may be too low. Correction for this for men with total asbestos dust exposures under 125 mppcf-years reduces the SMR for this group of men to 146.2. Data published by Haenszel, Loveland and Sirken (1962) for the year 1958 were used to make this correction.

Some additional help in evaluating the SMR of 166.7 for men with total dust exposures of under 125 mppcf-years also comes from a completely parallel study of 324 male retirees who worked as production or maintenance employees in the manufacture of a variety of building materials and were exposed to some dust, none of which contained asbestos or any substance suspected as being carcinogenic. Nine of these men died of respiratory cancer (ISC 162, 163) as compared with $5 \cdot 3$ expected, giving an SMR of $169 \cdot 8$.

The Figure combines data from Tables 2 and 3 and estimates the relationship between total asbestos dust exposure and respiratory cancer. Superimposed on the Figure is a freehand drawing of cumulative normal distribution-a distribution frequently used as a model for dose-response relationships.

If an SMR for cancer of the respiratory system of around 150 can be considered not excessive for men who spent most of their working life as production

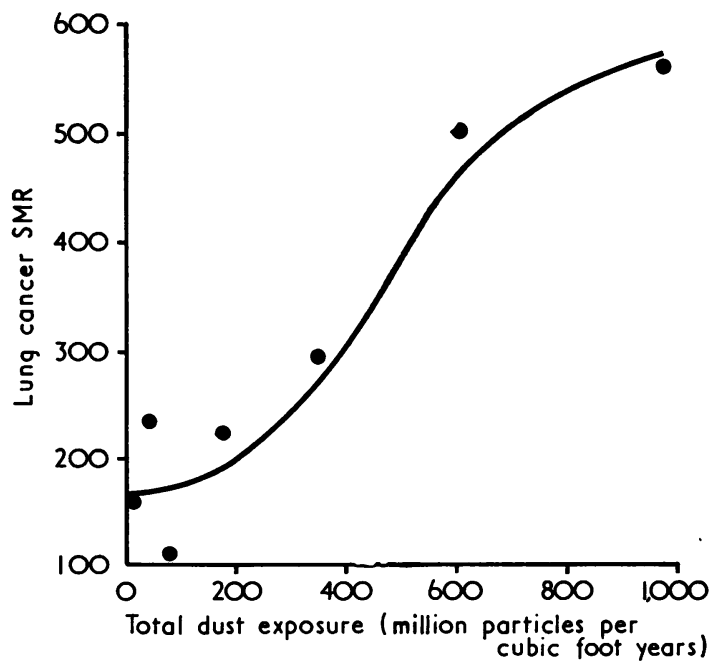

FIGURE Total asbestos dust exposure and lung cancer mortality. and maintenance workers in an occupation with a fair amount of dust, then it would appear that the TLV for respiratory cancer expressed in terms of total mppcf-years might be somewhere between 100 and 200 mppcf-years.

If the total dust estimate (mppcf-years) is separated into its two components, duration of exposure and average dust level, it is possible to test the assumption that time and dose should receive equal weight and are additive. This was done by constructing a $3 \times 3$ table with duration of exposure on one axis and average dust level on the other. For men in each of the nine cells in this table mean exposure years, mean exposure levels, and SMRs for respiratory cancer were calculated. From this it was possible to derive a linear multiple regression equation in which the SMR for respiratory cancer is the predicted or dependent variable. It is also possible to calculate correlation coefficients to see how well the combination of years worked and dust level predicts respiratory cancer excess, and how well each of these predicts respiratory cancer with the other held constant. These correlation coefficients are shown in Table 4.

TABLE 4

Degree of Relationship betWeen Time, Asbestos DUST LeVel, AND SMR FOR RESPIRATORY CANCER (ASSUMing a Linear MOdel)

\begin{tabular}{|c|c|c|c|}
\hline Predicting variables & Symbol & $\begin{array}{c}\text { Correlation } \\
\text { coefficient }\end{array}$ & $\begin{array}{l}\text { Per cent } \\
\text { variance } \\
\text { explained } \\
\left(R^{2} \text { or } r^{2}\right)\end{array}$ \\
\hline $\begin{array}{l}\text { Combination of time and } \\
\text { level } . \\
\text { Time at fixed level } \\
\text { Level at fixed time }\end{array}$ & $\begin{array}{l}R_{1.23} \\
r_{12.3} \\
r_{13.2}\end{array}$ & $\begin{array}{l}0.850 \\
0.738 \\
0.772\end{array}$ & $\begin{array}{l}0.722 \\
0.545 \\
0.596\end{array}$ \\
\hline
\end{tabular}

Recalling that a correlation coefficient ranges from 0 for no predictability to 1 for perfect predictability, it is apparent, first, that a linear combination of duration and level of exposure is a good predictor of respiratory cancer excess and, second, that exposure time with dust level held constant predicts nearly as well as dust level with exposure time held constant. The meaning of exposure time in this context is uncertain. Whether the contribution of time to the incidence of respiratory cancer is primarily a reflection of increasing dose or a reflection of an increasing latent period would be difficult to establish, although it seems probable that both factors are. involved.

An example of the use of the multiple regression equation is illustrated in Table 5 . Here predicted respiratory cancer SMRs are shown for men working 
TABLE 5

Predicted SMR for Respiratory CANCER for Men Working 25 Years at Selected Asbestos Dust LeVels (ASSUMing a Linear Model)

\begin{tabular}{c|c|c}
\hline $\begin{array}{c}\text { Dust level } \\
\text { (mppcf) }\end{array}$ & $\begin{array}{c}\text { Predicted SMR } \\
\text { (US expected) }\end{array}$ & $\begin{array}{c}\text { Predicted SMR } \\
\text { (US urban expected) }\end{array}$ \\
\hline 5 & $195 \cdot 3$ & $171 \cdot 3$ \\
10 & 257.8 & 226.2 \\
15 & 320.4 & 281.0 \\
20 & 383.0 & 335.9 \\
\hline
\end{tabular}

25 years at various asbestos dust levels. SMRs are shown where the expected mortality is based on all US white males and where the expected is based only on white males living in urban areas.

\section{Discussion}

These data are similar to those reported by McDonald et al. (1971). In their study, both time and dust level appeared to make independent contributions to respiratory cancer increments. While direct comparisons of excess respiratory cancer are not possible, it is possible to compare the range of estimates in relation to the range of total dust exposure. In both studies, age-corrected respiratory cancer mortality rates at the highest level of total dust exposure are roughly three times those at the lowest.

The study presented here was relatively simple to conduct since all records needed, with the exception of death certificates, were available in industry. Estimates of dust levels for jobs as they existed during periods long past are obviously very crude and numbers were in many instances very small. Nevertheless the results appear to be coherent.
Had larger numbers been available it might have been possible to identify more precisely a TLV for respiratory cancer in this type of population. The available data suggest, however, that large increments in respiratory cancer appear at a cumulative asbestos dust exposure of somewhere between 100 and 200 mppcf-years.

\section{References}

Doll, R. (1955). Mortality from lung cancer in asbestos workers. British Journal of Industrial Medicine, 12, 81-86.

Elwood, P. C., Cochrane, A. L., Benjamin, I. T., and Seys-Prosser, D. (1964). A follow-up study of workers from an asbestos factory. British Journal of Industrial Medicine, 21, 304-307.

Enterline, P. E. (1965). Mortality among asbestos products workers in the United States. Annals of the New York Academy of Sciences, 132, 156-165.

and Kendrick, M. A. (1967). Asbestos-dust exposures at various levels and mortality. Archives of Environmental Health, 15, 181-186.

Haenszel, W., Loveland, D. B., and Sirken, M. G. (1962). Lung-cancer mortality as related to residence and smoking histories. Journal of the National Cancer Institute, 28, 947-1001.

Knox, J. F., Holmes, S., Doll, R., and Hill I. D. (1968). Mortality from lung cancer and other causes among workers in an asbestos textile factory. British Journal of Industrial Medicine, 25, 293-303.

Mancuso, T. F., and Coulter, E. J. (1963). Methodology in industrial health studies. Archives of Environmental Health, 6, 210-226.

McDonald, J. C., McDonald, A. D., Gibbs, G. W., Siemiatycki, J., and Rossiter, C. E. (1971). Mortality in the chrysotile asbestos mines and mills of Quebec. Archives of Environmental Health, 22, 677-686.

Newhouse, M. L. (1969). A study of the mortality of workers in an asbestos factory. British Journal of Industrial Medicine, 26, 294-301.

Selikoff, I. J., Churg, J., and Hammond, E. C. (1964). Asbestos exposure and neoplasia. Journal of the American Medical Association, 188, 22-26.

Received for publication August 14, 1972.

Accepted for publication November 3, 1972. 